\title{
Commentary: The golden ratio
}

\author{
Tomasz A. Timek, MD, PhD
}

\footnotetext{
From the Division of Cardiothoracic Surgery, Spectrum Health, Grand Rapids, Mich; and Michigan State University College of Human Medicine, Grand Rapids, Mich.

Disclosures: Author has nothing to disclose with regard to commercial support.

Received for publication Dec 28, 2018; accepted for publication Dec 28, 2018; available ahead of print Feb 14, 2019.

Address for reprints: Tomasz A. Timek, MD, PhD, Division of Cardiothoracic Surgery, Spectrum Health, Michigan State University College of Human Medicine, 100 Michigan Ave NE, Grand Rapids, MI (E-mail: tomasz. timek@spectrumhealth.org).

J Thorac Cardiovasc Surg 2019;158:428-9

$0022-5223 / \$ 36.00$

Copyright (c) 2019 by The American Association for Thoracic Surgery

https://doi.org/10.1016/j.jtcvs.2018.12.089
}

Preoperative risk stratification of cardiothoracic patients has come to the forefront of the specialty as ever sicker patients are evaluated for complex cardiac procedures., Valvular surgery ${ }^{3}$ and advanced age ${ }^{4}$ pose particular clinical challenges. In this month's issue of the Journal, Wei and colleagues ${ }^{5}$ from Gangzhou, China, present the clinical outcomes of 949 patients older than 60 years who underwent valvular replacement for rheumatic heart disease. On the basis of earlier data, ${ }^{6}$ Wei and colleagues ${ }^{5}$ developed a ratio of preoperative uric acid level to lymphocyte count (ULR) as a predictor of postoperative mortality and morbidity. In this large patient cohort, Wei and colleagues ${ }^{5}$ found the ULR to be an independent predictor of patient survival, with an optimal cutoff value greater than 3.7 associated with mortality and adjusted odds ratios of 2.69 and 2.52 for in-hospital and 1-year mortalities, respectively. In-hospital death increased with each ULR tertile, but so did the complexity of surgical intervention, with the incidences of double and triple valve surgery substantially greater in the highest tertile. Although the extent of surgical intervention was not found to be a predictor of in-hospital mortality, pulmonary artery systolic pressure, a surrogate for advanced rheumatic valvular disease, was shown to be a significant prognosticator in both univariate and multivariate analyses. As both major adverse clinical event rate and 1-year mortality were largely driven by in-hospital death, this important influence of pulmonary hypertension on surgical outcomes should not be overlooked or minimized. Indeed, these same investigators ${ }^{7}$ found pulmonary artery pressure to be a strong predictor of in-hospital mortality in younger patients with rheumatic mitral valve disease.

Elevated uric acid levels have been associated with increased incidence of heart failure and adverse outcomes, ${ }^{8}$ potentially as a result of excessive oxidative stress ${ }^{9}$ and deleterious renal effects. ${ }^{10}$ Low lymphocyte count, a presumed marker of neurohormonal and cytokine activation and malnutrition, has been associated with increased mortality in patients with heart failure ${ }^{11,12}$ and those with severe chronic obstructive pulmonary disease. ${ }^{13}$ In its

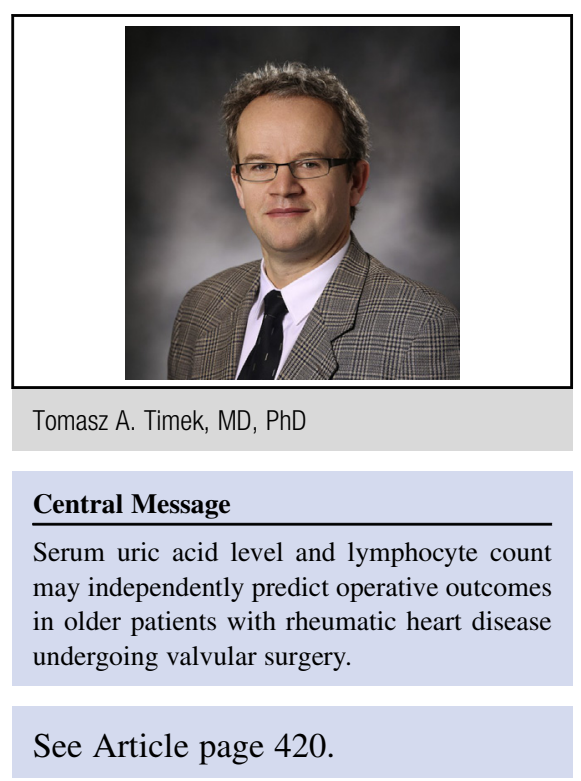

simplest form, both the numerator and the denominator of the presented ratio are a reflection of heart failure but with direct and inverse relationships, respectively. It is therefore not surprising that the resultant index was a powerful predictor of mortality in patients with rheumatic valve disease yet not superior to uric acid alone presented in the authors' previous work. ${ }^{5}$ In essence the ULR is a sheep in wolf's clothing, potentiating the effect of a potent prognosticator of clinical outcomes, heart failure, on postoperative mortality of patients with cardiac valvular disease. Interestingly, New York Heart Association functional class, a subjective measure of clinical heart failure, was only slightly inferior in predicting outcomes, but ULR was significantly superior to preoperative N-terminal pro-B-type natriuretic peptide levels. Although Society of Thoracic Surgeons Score was not calculated for these patients, the euroSCORE was used by Wei and colleagues ${ }^{5}$ and found not inferior to the ULR. This brings up the question of whether the ULR represents another in the plethora of preoperative risk indices or a physiologic indicator with potential for risk mitigation. Is the index generalizable across all cardiac surgical patients or specific to the more inflammatory etiology of rheumatic heart disease? Whether alterations of lymphocyte count with improved nutrition or reduction of uric acid with pharmacologic therapy could improve outcomes remains to be demonstrated. These parameters are, however, a reflection of the complex world of heart failure hemodynamic, humoral, and 
neuroendocrine milieu, elements that are not easily classified or affected. The formidable task of validating the ratio and demonstrating risk mitigation lies ahead of the authors. It is this process that will ultimately determine the ULR to be either a meaningful mathematical predictor or another pleasing ratio.

\section{References}

1. Ad N, Holmes SD, Patel J, Pritchard G, Shuman DJ, Halpin L. Comparison of EuroSCORE II, original EuroSCORE, and the Society of Thoracic Surgeons risk score in cardiac surgery patients. Ann Thorac Surg. 2016;102:573-9.

2. Guida P, Mastro F, Scrascia G, Whitlock R, Paparella D. Performance of the European system for cardiac operative risk evaluation II: a meta-analysis of 22 studies involving 145,592 cardiac surgery procedures. J Thorac Cardiovasc Surg. 2014;148:3049-57.

3. van Gameren M, Kappetein AP, Steyerberg EW, Venema AC, Berenschot EA, Hannan EL, et al. Do we need separate risk stratification models for hospital mortality after heart valve surgery? Ann Thorac Surg. 2008;85:921-30.

4. Afilalo J, Kim S, O'Brien S, Brennan JM, Edwards FH, Mack MJ, et al. Gait speed and operative mortality in older adults following cardiac surgery. JAMA Cardiol. 2016;1:314-21.

5. Wei XB, Chen WJ, Duan CY, Qin TH, Yu Y, Geng QS, et al. Joint effects of uric acid and lymphocyte count on adverse outcomes in elderly patients with rheumatic heart disease undergoing valve replacement surgery. J Thorac Cardi ovasc Surg. 2019;158:420-7.e1.

6. Wei XB, Jiang L, Liu YH, Feng D, He PC, Chen J, et al. Serum uric acid as a simple risk factor in patients with rheumatic heart disease undergoing valve replacement surgery. Clin Chim Acta. 2017;472:69-74.

7. Jiang L, Wei XB, He PC, Feng D, Liu YH, Liu J, et al. Value of pulmonary artery pressure in predicting in-hospital and one-year mortality after valve replacement surgery in middle-aged and aged patients with rheumatic mitral disease: an observational study. BMJ Open. 2017;7:e014316.

8. Huang H, Huang B, Li Y, Huang Y, Li J, Yao H, et al. Uric acid and risk of heart failure: a systematic review and meta-analysis. Eur J Heart Fail. 2014 16:15-24.

9. Borghi C, Rosei EA, Bardin T, Dawson J, Dominiczak A, Kielstein JT, et al. Serum uric acid and the risk of cardiovascular and renal disease. J Hypertens. 2015;33:1729-41; discussion 1741.

10. Kang DH, Chen W. Uric acid and chronic kidney disease: new understanding of an old problem. Semin Nephrol. 2011;31:447-52.

11. Huehnergarth KV, Mozaffarian D, Sullivan MD, Crane BA, Wilkinson CW, Lawler RL, et al. Usefulness of relative lymphocyte count as an independent predictor of death/urgent transplant in heart failure. Am J Cardiol. 2005;95:1492-5.

12. Acanfora D, Gheorghiade M, Trojano L, Furgi G, Pasini E, Picone C, et al. Relative lymphocyte count: a prognostic indicator of mortality in elderly patients with congestive heart failure. Am Heart J. 2001;142:167-73.

13. Acanfora D, Scicchitano P, Carone M, Acanfora C, Piscosquito G, Maestri R, et al. Relative lymphocyte count as an indicator of 3-year mortality in elderly people with severe COPD. BMC Pulm Med. 2018;18:116. 